\title{
Stimulus for change: Result of standardization of antimicrobial prophylaxis duration in pediatric cardiac surgery
}

\author{
Jennifer C. Romano, MD, MS
}

From the Department of Cardiac Surgery, University of Michigan, Ann Arbor, Mich.

Disclosures: Author has nothing to disclose with regard to commercial support.

Received for publication June 27, 2016; accepted for publication June 27, 2016; available ahead of print July 27, 2016.

Address for reprints: Jennifer C. Romano, MD, MS, Department of Cardiac Surgery, University of Michigan, 11-733 C. S. Mott Children's Hospital, 1540 E. Hospital Dr, SPC 4204, Ann Arbor, MI 48109-4204 (E-mail: jhirsch@umich.edu).

J Thorac Cardiovasc Surg 2016;152:1121-2 $0022-5223 / \$ 36.00$

Copyright (c) 2016 by The American Association for Thoracic Surgery http://dx.doi.org/10.1016/j.jtcvs.2016.06.051

Throughout the health care community, there is an increasing desire to reduce practice pattern variation through data-driven and validated protocols to minimize risk and improve outcomes. Antimicrobial prophylaxis has been among those areas of focus, especially as the numbers of antibiotic-resistant organisms and superinfections increase, along with interest in reducing the cost of health care delivery. As is often the case, the pediatric population tends to follow the adult population because of the inherent challenges in pediatric research and the heterogeneity of the patients. Within the trauma literature, limited antibiotic prophylaxis has been the standard since the 1990s. In adult cardiac surgery, prophylactic antibiotics have been limited to $<48$ hours by the Society of Thoracic Surgeons since 2006. ${ }^{1}$ However, neither we (ie, physicians who care for patients following congenital heart surgery) nor the Society of Thoracic Surgeons have provided the data or similar guidelines for pediatric populations.

The study by Bath and colleagues, ${ }^{2}$ although limited because it is a single-center, retrospective study, nicely demonstrates the ability, within the authors' health care system, to limit the duration of prophylaxis without negatively influencing outcomes. Most importantly, studies such as this are stimulating conversations at congenital heart centers around the country to consider doing the same. Although not as powerful as a multicenter randomized trial, studies such as this might generate the momentum to create change, with the end result of reducing practice pattern variation for antibiotic prophylaxis in the pediatric cardiac population nationwide. The challenge of any study attempting to standardize antibiotic prophylaxis duration is that there are so manyoften hard to delineate-additional variables that may influence surgical site infections. The differences can include simple things that are noted within the current study, ${ }^{2}$ such as bacitracin irrigation in the operating room

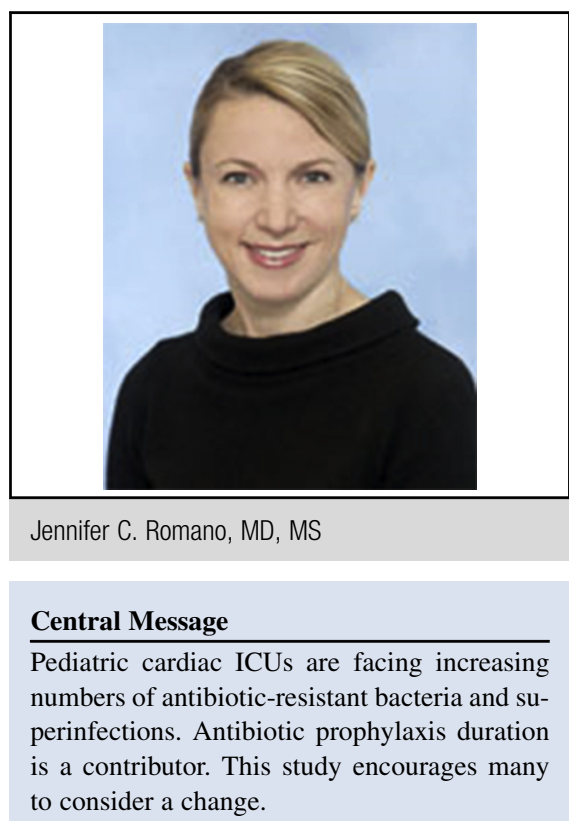

See Article page 1115 .

and type of surgical barrier/dressing used. Surgeons are well known for our desire to hold onto a same way, every day approach. This is ingrained in the hundreds of small decisions made every day in the management of patients that can influence colonization, surgical site protection, and wound management. It is the culmination of all of these small variables that have challenged and, to some degree, impeded progress in our profession toward standardizing antibiotic prophylaxis duration. My own center embarked on a study comparing 3 different antibiotic prophylactic regimens over the course of 3 years involving almost 4000 patients and found that those patients receiving antibiotics who had their regimen limited to 48 hours had the highest rate of surgical site and bloodstream infections. ${ }^{3}$ This study was well done with very compelling findings and as such has been referenced often since publication. The results of that study, which is now more than 10 years old, have continued to cast a shadow on our discussions about limiting antibiotic prophylaxis duration. A major shift in our intensive care unit leadership, our approach to external innovation, and increasing national pressures to minimize practice pattern 
variation has been required for us to take studies such as that by Bath and colleagues ${ }^{2}$ to heart. Pediatric cardiac intensive care units are facing increasing rates of antibiotic-resistant bacteria and superinfections previously limited to the adult world. Antibiotic prophylaxis duration is an important contributor. The study by Bath and colleagues ${ }^{2}$ will encourage many, including my own center, to consider a change.

\section{References}

1. Edwards FH, Engelman RM, Houck P, Shaian DM, Bridges CR, Society of Thoracic Surgeons. The Society of Thoracic Surgeons Practice Guidelines Series: Antibiotic prophylaxis in cardiac surgery, part 1: Duration. Ann Thorac Surg. 2006;81:397-404.

2. Bath S, Lines J, Loeffler AM, Malhotra A, Turner RB. Impact of standardization of antimicrobial prophylaxis duration in pediatric cardiac surgery. J Thorac Cardiovasc Surg. 2016;152:1115-20.

3. Maher KO, VanDerElzen K, Bove EL, Mosca RS, Chenoweth CE, Kulik TJ. A retrospective review of three antibiotic regimens for pediatric cardiac surgical patients. Ann Thorac Surg. 2002;74:1195-200. 